\title{
Correction: Social and juristic challenges of artificial intelligence
}

\author{
Matjaž Perc (1) ${ }^{1,2}$, Mahmut Ozer ${ }^{3,4} \&$ Janja Hojnik ${ }^{5}$
}

Correction to: Palgrave Communications https://doi.org/10.1057/s41599-019-0278-x, published online 25 June 2019

The original version of this Article contained an error in the author affiliations.

Janja Hojnik was incorrectly associated with Faculty of Natural Sciences and Mathematics, University of Maribor, Koroška cesta 160, Maribor, 2000, Slovenia.

The correct affiliation is listed below.

Faculty of Law, University of Maribor, Mladinska ulica 9, Maribor 2000, Slovenia.

The original version of this Article also contained errors in the reference Erkaymaz and Mahmut (2016), which was incorrectly given as:

Erkaymaz O, Mahmut O (2016) Impact of small-world network topology on the conventional artificial neural network for the diagnosis of diabetes. Chaos Solitons Fractals C (83):178-85. https://doi.org/10.1016/j.chaos.2015.11.029

The correct reference is listed below:

Erkaymaz O, Ozer M (2016) Impact of small-world network topology on the conventional artificial neural network for the diagnosis of diabetes. Chaos Solitons Fractals 83:178-85. https://doi.org/10.1016/j.chaos.2015.11.029

The referral to this reference is in the second paragraph of section "Under the hood of artificial intelligence".

The errors stated above have now been corrected in both the PDF and HTML versions of the Article.

Published online: 29 August 2019

\footnotetext{
(i) Open Access This article is licensed under a Creative Commons Attribution 4.0 International License, which permits use, sharing, adaptation, distribution and reproduction in any medium or format, as long as you give appropriate credit to the original author(s) and the source, provide a link to the Creative Commons license, and indicate if changes were made. The images or other third party material in this article are included in the article's Creative Commons license, unless indicated otherwise in a credit line to the material. If material is not included in the article's Creative Commons license and your intended use is not permitted by statutory regulation or exceeds the permitted use, you will need to obtain permission directly from the copyright holder. To view a copy of this license, visit http://creativecommons.org/licenses/by/4.0/.
}

(C) The Author(s) 2019

\footnotetext{
${ }^{1}$ Faculty of Natural Sciences and Mathematics, University of Maribor, Koroška cesta 160, Maribor 2000, Slovenia. ${ }^{2}$ Complexity Science Hub Vienna, Josefstädter Straße 39, Vienna 1080, Austria. ${ }^{3}$ Ministry of National Education, Ankara 06420, Turkey. ${ }^{4}$ Center for Artificial Intelligence and Data Science, Istanbul Technical University, Istanbul 34469, Turkey. ${ }^{5}$ Faculty of Law, University of Maribor, Mladinska ulica 9, Maribor 2000, Slovenia. Correspondence and requests for materials should be addressed to M.P. (email: matjaz.perc@um.si)
} 